\title{
COVID-19 and water
}

\author{
Bellie Sivakumar ${ }^{1}$ (D)
}

Published online: 9 July 2020

(C) Springer-Verlag GmbH Germany, part of Springer Nature 2020

\begin{abstract}
The 2019 coronavirus disease, called COVID-19, is caused by severe acute respiratory syndrome coronavirus 2 (SARSCoV-2). Since it was first identified in China in December 2019, COVID-19 has spread to almost all countries and territories and caused over 310,000 deaths, as on May 16, 2020. The impacts of the COVID-19 pandemic are now seen in almost every sector of our society. In this article, I discuss the impacts of COVID-19 on the water sector. I point out that our efforts to control the spread of COVID-19 will increase the water demand and worsen the water quality, leading to additional challenges in water planning and management. In view of the impacts of COVID-19 and other global-scale phenomena influencing water resources (e.g., global climate change), I highlight the urgent need for interdisciplinary collaborations among researchers studying water and new strategies to address water issues.
\end{abstract}

Keywords Infectious diseases · Coronavirus · COVID-19 · Water demand · Water quality

The 2019 coronavirus disease, called COVID-19, is caused by severe acute respiratory syndrome coronavirus 2 (SARS-CoV-2). The COVID-19 outbreak was identified in Wuhan, China, in December 2019 (World Health Organization 2020). The World Health Organization (WHO) declared the COVID-19 outbreak a Public Health Emergency of International Concern on January 30, 2020, and a pandemic on March 11, 2020. The COVID-19 pandemic is affecting almost the entire world. As on May 16, 2020, COVID-19 is affecting 213 countries and territories around the world and two international conveyances. There have been about 4.69 million cases of COVID-19 and 310,800 deaths, with about 1.80 million people recovered (www. worldometers.info/coronavirus).

According to WHO, COVID-19 spreads primarily from person to person through droplets released into the air when an infected person coughs, sneezes, or even speaks. People can catch COVID-19 if they breathe in these droplets from a person infected with the virus. These droplets are relatively heavy, generally do not travel more than a few feet, and they fall to the ground (or onto surfaces) in a few seconds-this is why social and physical distancing is considered effective in preventing the spread. These

Bellie Sivakumar

b.sivakumar@iitb.ac.in

1 Department of Civil Engineering, Indian Institute of Technology Bombay, Powai, Mumbai 400 076, India droplets can also land on objects and surfaces around the person, such as tables, doorknobs, and handrails. People can become infected by touching these objects or surfaces, then touching their eyes, nose or mouth. This is why it is important to wash one's hands regularly with soap and water or clean with alcohol-based hand rub.

The spread of COVID-19 and resulting mortality in a region is influenced by many factors, including the general health of the people, the personal and environmental opportunities for the spread, and the type of treatment and welfare schemes available. For instance, people with good health (generally young people) are less affected by COVID-19, while people with pre-existing health conditions (e.g., diabetes, kidney diseases, high blood pressure, cancer) are affected more; indeed, far greater percentages of deaths have been reported among elder people and those with pre-existing conditions when compared to younger people and those with good health. High population density (which influences the distance between people), low temperature (which facilitates the spread of the virus), and less water/disinfectants generally lead to more spread.

Numerous studies have examined the spread, impact, and control of COVID-19. Such studies have addressed a wide variety of aspects. These include: how population flow drives the distribution of COVID-19 (e.g., Jia et al. 2020); effects of travel restrictions on the spread of COVID-19 outbreak (e.g., Chinazzi et al. 2020); links between climate factors and COVID-19 spread (e.g., Bashir et al. 2000; Wu et al. 2020); drug development 
against COVID-19 (e.g., Abd El-Aziz and Stockland 2020); and plight of migrants and refugees during COVID19 and calls for their inclusion in response to COVID-19 (e.g., Orcutt et al. 2020); and impact of lockdown on the environment, including surface water quality and air quality (e.g., Yunus et al. 2019; Mahato et al. 2020; Muhammad et al. 2020).

In the context of COVID-19 spread and control, water plays a particularly important role. This is because, according to WHO (and governments around the world), one of the most effective ways to reduce one's chances of being infected or spreading COVID-19 is to regularly and thoroughly wash one's hands with soap and water or clean them with an alcohol-based hand rub. Washing one's hands with soap and water or using an alcohol-based hand rub kill viruses that may be on one's hands. Therefore, the availability and accessibility of water can significantly influence the extent of spread of COVID-19 in a region. In this regard, developing and under-developed regions have a particular disadvantage, since the accessibility to water in such regions, even for the most basic needs (e.g., drinking, sanitation), is generally limited (e.g., Sivakumar 2011a). It is also important to note that these are also the regions generally with high population and population density. Therefore, mitigating or controlling the spread of COVID19 is highly challenging in these regions, as it necessitates identifying, accessing, and supplying significant quantity of additional water resources all around (not to mention the social-distancing).

Despite this, I believe, the issues associated with water demand and supply to tackle COVID-19 has not gained serious attention until now. A key reason for this may be the so-called "lockdown" or "stay-at-home" restriction that has been and continues to be imposed in many countries (at national level or local levels), including in some of the most populous countries, such as China, India, and the United States. The lockdown has forced almost the entire population in many countries to stay at home. This has greatly reduced the need for washing or cleaning one's hands and, hence, reduced the need for additional water use. This situation will certainly change, however, once the lockdown is partially relaxed or completely removed. Once people start going out of their homes to their workplaces and other public places, as was before, they will realize the need to wash their hands more often and, thus, will need more water. This will be not only in their workplaces and other public places but also at their own homes, since they will have to wash their hands after returning to their homes from outside, to make sure they are not spreading the virus at home. It is important, therefore, to ask whether there are enough water facilities in workplaces and other public places (and also at their homes) for everyone for the foreseeable future. This question assumes particular significance, since COVID-19 will likely last for years (not just months), according to many health professionals, epidemiologists, and others in fields related to infectious diseases and their effects. Indeed, there are concerns that COVID-19 may never go away and that we will have to get used to living a "new normal" way of life, i.e. "living with COVID-19."

This means that our demands for water will significantly increase in the future, especially in the domestic, industrial, and recreational sectors. For instance, considering a country like India, with a population of over 1.3 billion, even a small amount of additional water requirement for washing one's hands will increase the water demand by at least a few billions of liters. With the already significant demand for water for the agricultural sector, which currently uses more than $70 \%$ of water globally (and even more than $90 \%$ in some regions), there will be enormous pressure on our water resources. This raises several important questions: Where can we find the additional water resources? How to bring the water to where it will be needed (both urban and rural areas, and throughout the countries)? What will be the additional water storage and treatment facilities required for water supply? How much will it cost? Will water pricing need to be introduced (or increased) to cover the costs, where water pricing currently does not exist (or where there is already water pricing)? How will the society respond to water pricing, especially when it is introduced for the first time in a region, as in many developing and under-developing regions?

In addition to the increase in the demands for water quantity it imposes, COVID-19 also presents challenges from the perspective of water quality. For instance, use of more water (and also soap and disinfectants) to wash one's hands to control the spread of COVID-19 will increase the quantity of wastewater, with perhaps even poorer quality, coming from homes, workplaces, and other public places. This will, in turn, increase the required capacities of sewer/ drainage structures and wastewater treatment facilities, before such wastewater can be discharged safely to appropriate places, including to nearby water courses. This means, there will be additional costs for such potentially new drainage and treatment facilities required. It is relevant to note, at this point, that in many developing and underdeveloped regions, it is common for the untreated wastewater (particularly from many industries, but also from homes) to be discharged into the nearby water courses. Assuming that this trend will continue, at least for the foreseeable future, the additional quantity and poorer quality of wastewater will have serious effects on water quality in nearby water bodies, including rivers and lakes. It is indeed encouraging to note that the quality of water in rivers, lakes, and other water bodies around the world, especially in developing and under-developed regions, 
have significantly improved during the lockdown period [e.g., Yunus et al. (2020)]. This, however, is only temporary, and there is no doubt that the situation will become "normal" again once the lockdown is over!

Furthermore, there are serious concerns about the handling and disposal of products and materials used to control the spread of COVID-19 and to treat the COVID-19 patients (e.g., face masks, hand gloves, and personal protective equipment) after their use. This is because their collection, handling, and disposal are dangerous and require undertaking extreme precautions. It is also important to note that disposing the bodies of COVID-19 patients after their death has been an enormously challenging and excruciating experience, as has been witnessed in many places around the world. Handling and disposal of wastes related to COVID-19 often require a large quantity of water, both during and after.

The above observations suggest that COVID-19 will have serious impacts on the water sector, in terms of both water quantity and water quality. This will bring new and enormous challenges to water planning, management, and governance. Such challenges include aspects related to water sources, infrastructure for storage and distribution, sewer/drainage structures, wastewater treatment and disposal, and water pricing, among others. It is also appropriate to note, at this point, that there are already significant challenges in water planning and management, due to population growth and improving living standards. Global climate change is anticipated to bring its own challenges to the water sector (e.g., Sivakumar 2011b), in terms of both water quantity and water quality. There are also concerns about our ability to produce food and generate energy to meet the future demands, which depend, to a great extent, on water (for irrigation and hydroelectricity) (Chen et al. 2016).

How will all these affect our future water planning and management activities, especially if COVID-19 and its impact last for a long time? Will totally new planning and management strategies be needed, and in what shape and form? What can the governments around the world do to address these? What can the water managers do? What can the people do? These are some of the basic questions policy makers, water managers, environmentalists, non-governmental organizations, and also common people should be starting to ask. Needless to say, water researchers have a particularly important role in asking these questions and in finding solutions. There is no question that this will require interdisciplinary collaborations among water researchers from diverse fields, including earth sciences, engineering, economics, law, social sciences, and psychology. While there have already been some efforts towards such interdisciplinary collaborations to address water issues, there is still a long way to go, especially in view of any new globalscale disasters, such as the COVID-19 pandemic.

Looking at the exponential developments we have recently made in diverse fields, especially in technology and medicine, not many people would have imagined that an infectious disease would almost literally "lockdown" the entire world and force us to "stay at home." However, that is exactly what is happening now. What is even more, we cannot be sure that this kind of thing will never happen again. Indeed, something may just be lurking around to cause havoc! Whether infectious disease or other, water seems to offer solutions to almost all the problems on the Earth. However, where to find solutions when the problem is water itself? We indeed need to have a long vision to look after and take care of our precious water. I hope we will steer our efforts in this direction much more than we have until now. If we do not have water to wash our hands, then we will be washing our hands of our problems!

\section{References}

Abd El-Aziz TM, Stockland JD (2020) Recent progress and challenges in drug development against COVID-19 coronavirus (SARS-CoV-2) - an update on the status. Infect Genet Evol 83:104327

Bashir MF, Ma B, Bilal, Komal B, Bashir MA, Tan D, Bashir M (2000) Correlation between climate indicators and COVID-19 pandemic in New York, USA. Sci Total Environ 728:138835

Chen J, Shi H, Sivakumar B, Peart MR (2016) Population, water, food, energy and dams. Renew Sustain Energy Rev 56:18-28

Chinazzi M, Davis JT, Ajelli M, Gioannini C, Litvinova M, Merler S, y Piontti AP, Mu K, Rossi L, Sun K, Viboud C, Xiong X, Yu H, Halloran ME, Longini IM, Vespignani A (2020) The effect of travel restrictions on the spread of the novel 2019 coronavirus (COVID-19) outbreak. Science 368(6489):395-400

Jia JS, Lu X, Yuan Y, Xu G, Jia J, Christakis NA (2020) Population flow drives spatio-temporal distribution of COVID-19 in China. Nature. https://doi.org/10.1038/s41586-020-2284-y

Mahato S, Pal S, Ghosh KP (2020) Effect of lockdown amid COVID19 pandemic on air quality of the megacity Delhi, India. Sci Total Environ 730:139086

Muhammad S, Long X, Salman M (2020) COVID-19 pandemic and environmental pollution: a blessing in disguise? Sci Total Environ 728:138820

Orcutt M, Patel P, Burns R, Hiam L, Aldridge R, Devakumar D, Kumar B, Spiegel P, Abubakar I (2020) Global call to action for inclusion of migrants and refugees in the COVID-19 response. Lancet 395(10235):1482-1483

Sivakumar B (2011a) Water crisis: from conflict to cooperation-an overview. Hydrol Sci J 56(4):531-552

Sivakumar B (2011b) Global climate change and its impacts on water resources planning and management: assessment and challenges. Stoch Env Res Risk Assess 25(4):583-600

World Health Organization (WHO) (2020) Novel coronavirusChina. https://www.who.int/csr/don/12-january-2020-novel-coro navirus-china/en/

Wu Y, Jing W, Liu J, Ma Q, Yuan J, Wang Y, Du M, Liu M (2020) Effects of temperature and humidity on the new daily cases and 
deaths of COVID-19 in 166 countries. Sci Total Environ 729:139051

Yunus AP, Masago Y, Hijioka Y (2020) COVID-19 and surface water quality: improved lake water quality during the lockdown. Sci Total Environ 731:139021
Publisher's Note Springer Nature remains neutral with regard to jurisdictional claims in published maps and institutional affiliations. 